\section{New JAOA section to focus on federal activities}

With this issue, JAOA begins publication of a monthly "Federal Update" column. It will feature significant news from the federal government. The initial emphasis will be on Food and Drug Administration (FDA) material.

\section{See Federal Update on page $\mathbf{2 8 1}$}

The FDA items will be brief and related to regulatory activities. Of primary interest will be marketing approvals and labeling changes on new drugs. But, the section will also focus on FDA actions on new medical instrumentation, products resulting from developments in the biotechnology field, and problems with the food supply. Obviously, the everyday practices of osteopathic physicians are significantly affected by such information.

Because medical practice surely will become more sophisticated as it heads toward the 21 st century, so may FDA activities expand to reflect these changes. We expect that this section will serve as a continuing conduit of important news.

Although the "Federal Update" section will emphasize the FDA, other health-related arms of the government will be featured periodically: the Centers for Disease Control, the Health Resources and Services Administration, the National Institutes of Health, and the Health Care Financing Administration.

The section represents the beginning of important changes to make JAOA more relevant to each osteopathic physician. We welcome your comments about it and your suggestions about how we can serve you better.

THOMAS WESLEY ALLEN, DO

\section{Spring brings a breath of smoke-free air on campus}

The movement toward a smoke-free environment continues. On the first day of spring, March 20, 1989, the University of Medicine and Dentistry of New Jersey and its School of Osteopathic Medicine will join four other colleges of osteopathic medicine which ban smoking in all of their facilities. These include the New York College of Osteopathic Medicine of the New York Institute of Technology, the Southeastern University of Health Sciences Southeastern College of Osteopathic Medicine, the Texas College of Osteopathic Medicine, and the University of Osteopathic Medicine and Health Sciences College of Osteopathic Medicine and Surgery.

A recent JAOA survey revealed that all but one of the remaining 11 colleges of osteopathic medicine ban smoking in common areas. However, smoking is allowed in restricted areas, such as private offices and lounges.

Kudos to these institutions that have gone "smoke free." Too many health-related institutions have failed to follow this lead which would illustrate their sincere commitment to health.

Health promotion and disease prevention are not new concepts to osteopathic physicians. Our philosophical foundations are based on the ancient tenet of prevention. We must take the lead in demonstrating health practices that benefit our patients, employees, and visitors alike.

The case against smoking remains clear. Let us accept the challenge to make every health care institution-from physicians' offices to medical schools - completely smoke-free.

THOMAS WESLEY ALLEN, DO 


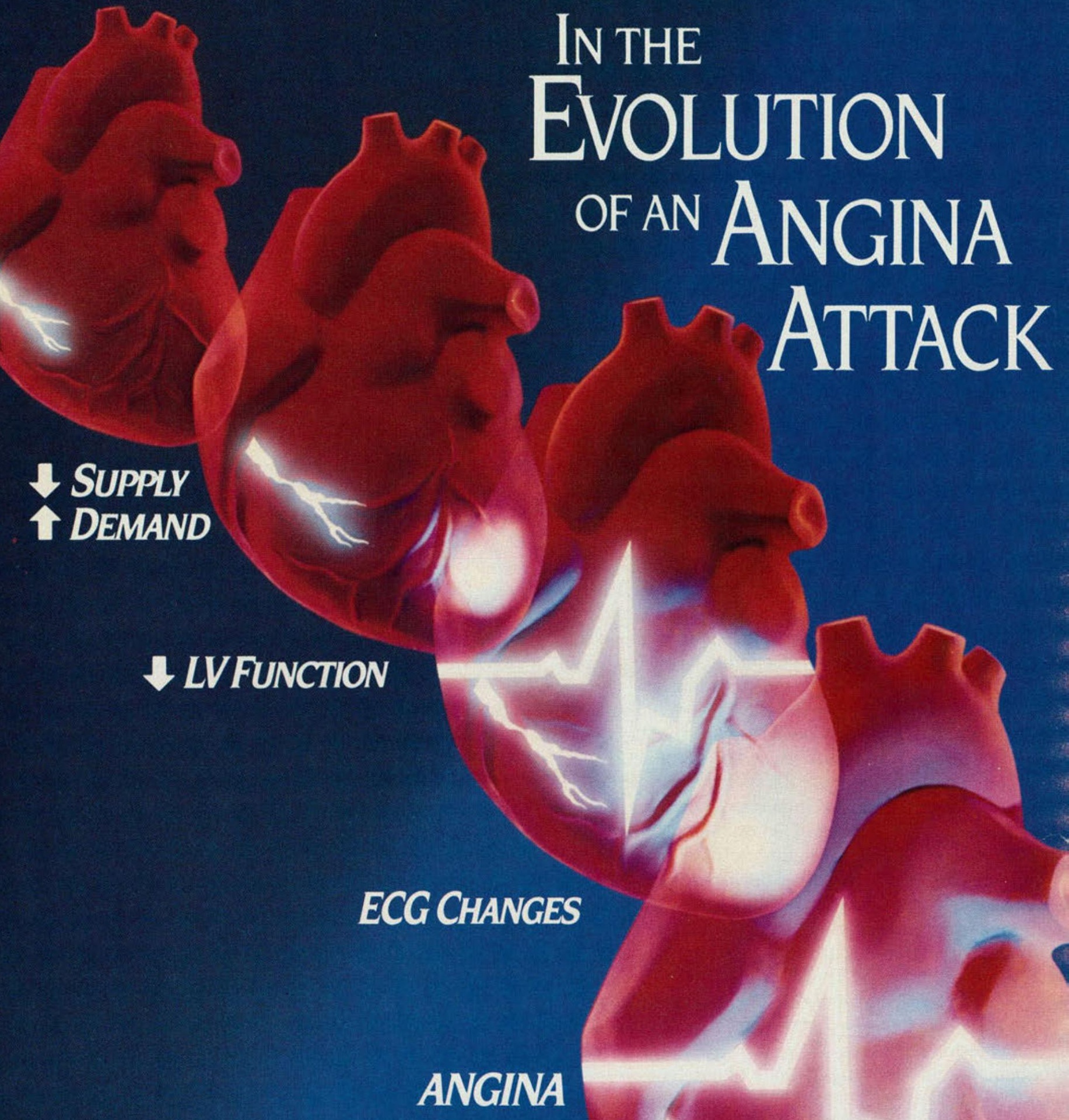




\section{PROCARDIA (NIFEDIPINE) PREVENTS THE PAIN... Protects THE Angina Patient AT EVERY STAGE}

SUPPLYIDEMAND - PROCARDIA increases myocardial oxygen supply and reduces demand

LV Function o PROCARDIA helps to maintain or enhance parameters of left ventricular function'

ECG Changes

- PROCARDIA decreases the incidence of ischemic ECG changes ${ }^{2}$

ANGINA

- PROCARDIA reduces episodes of both painful and painless ischemia ${ }^{3.4}$

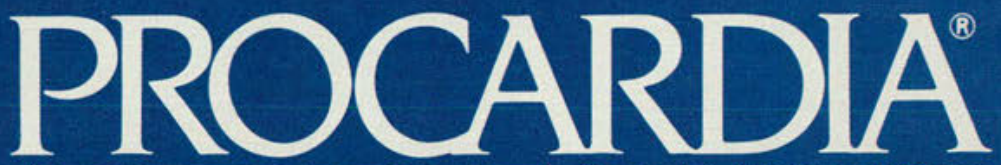

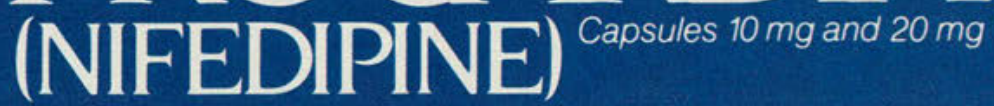

Prevents THE PAin...

Protects the Angina Patient 
